\title{
Poor Survival after Reirradiation
}

National Cancer Institute

\section{Source}

National Cancer Institute. Poor Survival after Reirradiation. NCI Thesaurus. Code C127868.

A score of 3 on the Combs Prognostic Index scale. 